\title{
A randomised controlled trial of high versus low long chain triglyceride whole protein feed in active Crohn's disease
}

\author{
K Leiper, J Woolner, M M C Mullan, T Parker, M van der Vliet, S Fear, J M Rhodes,
} $\mathrm{J} O$ Hunter

\begin{abstract}
Background-Polymeric feeds have shown variable efficacy in active Crohn's disease (CD) with remission rates from $36 \%$ to $82 \%$. Meta-analyses of elemental, peptide, and whole protein feeds have shown a strong negative correlation between remission rate in $\mathrm{CD}$ and the long chain triglyceride (LCT) content of the feed. We performed a randomised controlled double blind trial in patients with active CD comparing two single whole protein feeds with LCT supplying $5 \%$ or $30 \%$ of the total energy.
\end{abstract}

Methods-Fifty four patients with active CD (Crohn's disease activity index (CDAI) $>200$, serum $C$ reactive protein (CRP) $10 \mathrm{mg} / \mathrm{l}$ ) were randomised to a high or low LCT feed for three weeks. The total amount of energy supplied by fat was identical in the two feeds. Remission was defined as a CDAI $\leqslant 150$ and response as a fall in CDAI of $\geqslant 70$ or a CRP $<10 \mathrm{mg} / 1$.

Results-Overall remission rate by intention to treat was $26 \%$ for the low LCT feed and $33 \%$ for the high LCT feed $(p=0.38)$. Response was achieved in $33 \%$ with the low LCT and in $52 \%$ with the high LCT feed $(p=0.27)$. CRP $<10 \mathrm{mg} / 1$ was achieved in $30 \%$ in the low LCT and $33 \%$ in the high LCT group $(p=0.99)$. Thirty nine per cent (21/54) of patients withdrew before three weeks because of inability to tolerate the diet. Excluding patients unable to tolerate the diet, remission rates were $46 \%$ for low LCT and $45 \%$ for high LCT $(p=0.99)$.

Discussion-This trial has shown no difference in the effect of low and high LCT whole protein feeds in active $C D$. The previously reported correlation between LCT content of diet and response in active $C D$ is unlikely to be due to LCT itself and may be due to some other component of high LCT feeds.

(Gut 2001;49:790-794)

Keywords: Crohn's disease therapy; polymeric feeds; dietary fat

In active Crohn's disease (CD), elemental (amino acid based) diets have shown effectiveness equivalent to that of corticosteroids in some studies, with remission rates of $80 \%$ or more in compliant patients. ${ }^{1-3}$ Polypeptide and polymeric (whole protein) diets are more palatable than elemental feeds but trials have shown very variable results with remission rates of $36-82 \%{ }^{4-8}$

Fernández-Bañares et al first proposed that a possible cause of the disparity in response to different enteral feeds may be differences in fat content of the feeds. ${ }^{9}$ Two subsequent independent meta-analyses have shown a striking inverse correlation between remission rates in active $\mathrm{CD}$ and the long chain triglyceride (LCT) content of elemental or polymeric feeds. ${ }^{10}{ }^{11}$ This effect was especially noticeable when LCT contributed more than $15 \%$ of the total energy of the feed. Further support for the possible inflammatory effects of LCT comes from a study in pigs with an antiperistaltic ileal segment which developed intestinal inflammation in response to high fat feeding. ${ }^{12}$ Other animal studies have shown that LCT absorption is associated with enhanced lymphocyte migration, upregulation of adhesion molecules, and stimulation of lymphocyte function. ${ }^{13}$

We therefore conducted a two centre double blind randomised controlled trial to compare the effect on active CD of two whole protein liquid enteral feeds which differed only in the percentage of energy provided as LCT ( $5 \%$ and $30 \%$, respectively).

\section{Methods}

PATIENTS

With approval from the Liverpool and Cambridge local ethics committees and informed consent, patients with active CD were randomised to receive either a high or low LCT liquid diet as sole food intake for three weeks. Inclusion criteria were age $>18$ years, CD activity index (CDAI) $\geqslant 200,{ }^{14}$ and serum C reactive protein (CRP) $\geqslant 10 \mathrm{mg} / \mathrm{l}$. Patients receiving corticosteroids or 5-aminosalicylic acid preparations had received a stable dose for the previous four weeks and patients receiving azathioprine had received a stable dose for more than three months. Patients were included if the corticosteroid dose was prednisolone $\leqslant 10 \mathrm{mg} /$ day or budesonide $\leqslant 6$ $\mathrm{mg} /$ day, and the dose was kept constant for the duration of the trial. Exclusion criteria included: complications requiring surgery (obstruction or perforation), use of long term corticosteroids for other diseases, pregnancy or

Abbreviations used in this paper: $\mathrm{CD}$, Crohn's disease; LCT, long chain triglyceride; MCT, medium chain triglyceride; CDAI, Crohn's disease activity index; HBI, Harvey Bradshaw index; VHAI, Van Hees activity index; CRP, $C$ reactive protein. 
lactation, solitary rectal CD, and any long term medication for other diseases.

TRIAL PROTOCOL

Randomisation was conducted at each centre, using randomisation tables, by a designated pharmacist who had no other involvement in the trial. Patients were stratified for concurrent corticosteroid or immunosuppressive therapy, severity (CDAI >250) and disease location (ileum only, ileocolonic, colon only). Feeds were taken by mouth but those unable to tolerate them orally could be fed via a nasogastric tube. No other food or drink was allowed other than water and up to two cups per day of black decaffeinated coffee, tea, or herbal/non-citrus fruit tea. A physical examination was performed and laboratory and clinical indices checked at days 0 (pretreatment), 7, 14, and 21. Patients whose CDAI fell by $>70$ points by day 21 but had not achieved remission were offered a further seven days of feed.

\section{FEEDS}

Patients were randomised to receive a feed containing either $5 \%$ or $30 \%$ of energy in the form of LCT (Scientific Hospital Supplies, Liverpool, UK) with the balance in total fat made up by medium chain triglycerides (MCT). The protein component of both feeds was derived from casein and the MCT was derived from fractionated coconut oil. The LCT source was soyabean oil for the $5 \%$ LCT feed and a blend of palm and canola oils for the $30 \%$ LCT feed. The fatty acid composition of the feeds is shown in table 1 . The two feeds were flavoured with natural or nature identical flavours (chocolate, strawberry, and vanilla) with appropriate sweeteners and acidity regulators. The two feeds were identical in colour, packaging, carbohydrate, total fat, minerals, trace elements, and vitamin content. Estimation of the quantity of feed needed for each patient was determined by standard methods. ${ }^{1516}$

\section{OUTCOME MEASURES}

The primary outcome measure was remission, as defined by a CDAI of $\leqslant 150$ after three weeks of therapy. Secondary outcome measures were reduction in CDAI of $\geqslant 70$, a Harvey Bradshaw index (HBI) of $<4,{ }^{17}$ reduction in

Table 1 Composition of feeds

\begin{tabular}{|c|c|c|}
\hline Nutrient per $100 \mathrm{~g}$ & $5 \%$ LCT & $30 \%$ LCT \\
\hline Energy per $100 \mathrm{~g} \mathrm{~kJ}$ (kcal) & $1897 \quad(452)$ & $1897 \quad 452)$ \\
\hline Protein equivalent $(\mathrm{g})$ & 18 & 18 \\
\hline Carbohydrate (g) & 55.5 & 55.5 \\
\hline Fat $(\mathrm{g})$ & 17.5 & 17.5 \\
\hline Fibre & Nil & Nil \\
\hline \multicolumn{3}{|l|}{ Fatty acid profile (\%) } \\
\hline $\mathrm{C}_{6}$ & 0.1 & $<0.1$ \\
\hline $\mathrm{C}_{8}^{\circ}$ & 51 & 9 \\
\hline $\mathrm{C}_{10}$ & 35 & 6 \\
\hline $\mathrm{C}_{12}^{10}$ & 0.1 & 0.2 \\
\hline $\mathrm{C}_{14}$ & - & - \\
\hline $\mathrm{C}_{16: 0}$ & 1.5 & 34.5 \\
\hline $\mathrm{C}_{16: 1}$ & - & - \\
\hline $\mathrm{C}_{18: 0}$ & 0.5 & 4 \\
\hline $\mathrm{C}_{18: 1}$ & 3.4 & 35.5 \\
\hline $\mathrm{C}_{18: 2}(\mathrm{n} 6)$ & 7.4 & 9.5 \\
\hline $\mathrm{C}_{18: 3}^{18}(\mathrm{n} 3)$ & 1 & 1.2 \\
\hline
\end{tabular}

LCT, long chain triglyceride.
Table 2 Baseline characteristics of the patients in the low and high long chain triglyceride (LCT) groups (mean values)

\begin{tabular}{lccl}
\hline & $\begin{array}{c}\text { Low LCT } \\
(n=27)\end{array}$ & $\begin{array}{c}\text { High LCT } \\
(n=27)\end{array}$ & $p$ Value \\
\hline Age (y) & 36.9 & 35.6 & 0.71 \\
CDAI & 300 & 335 & 0.14 \\
VHAI & 175 & 188 & 0.25 \\
HBI & 8.9 & 11.2 & $0.03^{\star}$ \\
QOL score & 123 & 112 & 0.27 \\
Weight (kg) & 60.9 & 64.2 & 0.44 \\
BMI & 21.5 & 22.3 & 0.56 \\
Albumin (g/l) & 36 & 34 & 0.17 \\
Haemoglobin (g/dl) & 12.1 & 12.0 & 0.85 \\
CRP (mg/l) & 52.7 & 52.8 & 0.99 \\
ESR (mm/h) & 37.4 & 42.7 & 0.49 \\
WBC ( $\left.10^{9} / 1\right)$ & 8.7 & 9.5 & 0.39 \\
Current smokers (n) & 8 & 8 & \\
Drug therapy (n) & & & \\
$\quad$ 5-ASA & 11 & 10 & \\
$\quad$ Steroids & 6 & 4 & \\
Azathioprine & 4 & 4 & \\
Site of disease (n) & & & \\
$\quad$ Ileal & 9 & 6 & \\
$\quad$ Ileocolonic & 12 & 12 & \\
Colonic & 6 & 9 & \\
\hline
\end{tabular}

CDAI, Crohn's disease activity index; HBI, Harvey Bradshaw index; VHAI, Van Hees activity index; QOL, quality of life; BMI, body mass index; CRP, C reactive protein; ESR, erythrocyte sedimentation rate; WBC, white blood cells; 5-ASA, 5-aminosalicylic acid.

${ }^{\star}$ Significant difference.

van Hees activity index (VHAI), ${ }^{18}$ CRP $<10$ $\mathrm{mg} / \mathrm{l}$, and improvement in inflammatory bowel disease quality of life index score. ${ }^{19}$

\section{TREATMENT FAILURES}

Treatment failures were defined as a CDAI $>150$ after three weeks on the feed. Patients could withdraw from the trial if they could not tolerate the feed or were unable to consume at least $50 \%$ of their estimated daily energy requirement for a week on two consecutive weeks. The supervising physician could withdraw the patient if clinically significant deterioration occurred during the trial.

\section{POWER CALCULATION}

The initial plan was to recruit 52 patients in each group to give $90 \%$ power of excluding a significant difference $(p<0.05)$ of $50 \%$ to $80 \%$ response between the two diets. ${ }^{20} \mathrm{~A}$ halfway blinded interim analysis showed no trend for any differences between the two treatment groups and the trial was therefore terminated and the treatment codes broken.

\section{STATISTICAL ANALYSIS}

Data for response to feeds were analysed as intention to treat and also as adjusted for withdrawals due to inability to tolerate the feed. Analysis of quantitative data between groups was performed using $t$ tests with the exception of CRP where the Mann-Whitney U test was used. Analysis of response rate between groups was by $\chi^{2}$ test.

\section{Results}

Fifty four patients were recruited in the two centres: 24 from Liverpool and 30 from Cambridge. Twenty seven patients each were randomised to high and low LCT feeds (table 2). There were no significant differences between groups in pretreatment CDAI, VHAI, 
Table 3 Response to low and high long chain triglyceride (LCT) feeds: intention to treat analysis

\begin{tabular}{llccc}
\hline & $\begin{array}{l}\text { Low LCT (\%) } \\
(n=27)\end{array}$ & $\begin{array}{l}\text { High LCT (\%) } \\
(n=27)\end{array}$ & $\begin{array}{l}\text { Difference }(95 \% \text { CI) in } \\
\% \text { response (low-high) }\end{array}$ & p Value \\
\hline CDAI $\leqslant 150$ & $7(26)$ & $9(33)$ & $-7(-37,21)$ & 0.77 \\
CDAI fall $\geqslant 70$ & $9(33)$ & $14(52)$ & $-19(-48,11)$ & 0.27 \\
HBI $<4$ & $8(30)$ & $10(37)$ & $-7(-36,21)$ & 0.77 \\
CRP $<10 \mathrm{mg} / 1$ & $8(30)$ & $9(33)$ & $-3(-32,25)$ & 0.99 \\
\hline
\end{tabular}

CDAI, Crohn's disease activity index; HBI, Harvey Bradshaw index; CRP, C reactive protein.

Table 4 Response to low and high long chain triglyceride (LCT) feeds: excluding patients who were not able to tolerate the feeds

\begin{tabular}{lllll}
\hline & $\begin{array}{l}\text { Low LCT (\%) } \\
(n=13)\end{array}$ & $\begin{array}{l}\text { High LCT (\%) } \\
(n=20)\end{array}$ & $\begin{array}{l}\text { Difference (95\% CI) in \% } \\
\text { response (low-high) }\end{array}$ & p Value \\
\hline CDAI $\leqslant 150$ & $6(46)$ & $9(45)$ & $1(-37,41)$ & 0.99 \\
CDAI fall $\geqslant 70$ & $6(46)$ & $9(45)$ & $1(-37,41)$ & 0.99 \\
HBI $<4$ & $6(46)$ & $9(45)$ & $1(-37,41)$ & 0.99 \\
CRP $<10 \mathrm{mg} / 1$ & $5(38)$ & $7(35)$ & $3(-34,41)$ & 0.99 \\
\hline
\end{tabular}

CDAI, Crohn's disease activity index; HBI, Harvey Bradshaw index; CRP, C reactive protein.

or serum CRP but mean HBI was 8.9 in the low LCT group versus 11.2 in the high LCT group ( $\mathrm{p}=0.03, t$ test). Overall results are shown in tables 3 and 4 .

CROHN'S DISEASE ACTIVITY INDEX

The primary end point of CDAI $\leqslant 150$ was achieved in $26 \%$ of the low LCT group and in $33 \%$ of the high LCT group ( $p=0.38, \chi^{2}$ test)
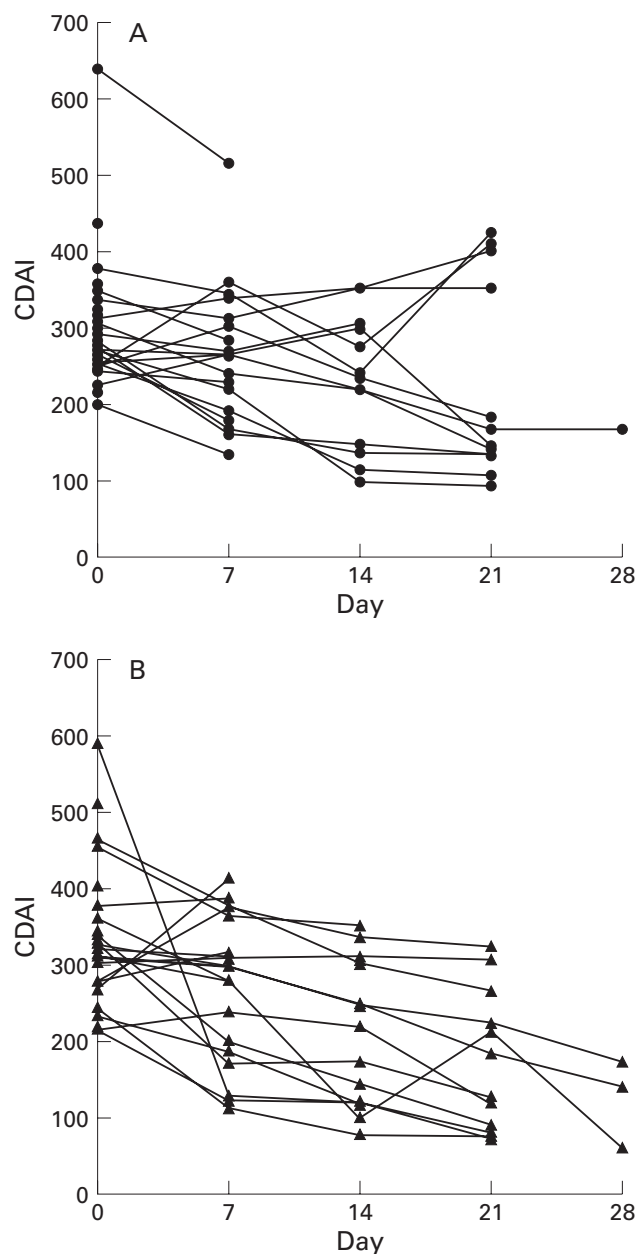

Figure 1 Individual patient Crohn's disease activity index (CDAI) response to low $(A)$ and high $(B)$ long chain triglyceride containing polymeric feeds.
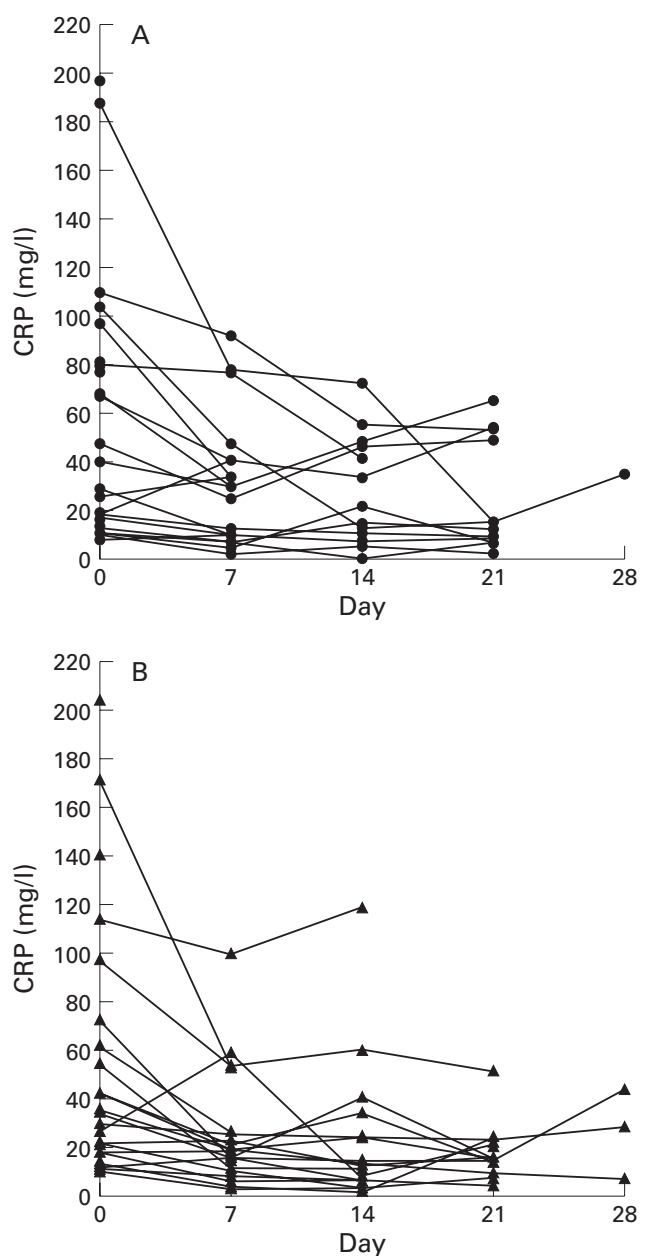

Figure 2 Individual patient serum $C$ reactive protein $(C R P)$ response to low $(A)$ and high $(B)$ long chain triglyceride containing polymeric feeds.

by intention to treat analysis. Response, defined as a fall in CDAI of $\geqslant 70$ points, was achieved in $33 \%$ of the low LCT and $52 \%$ of the high LCT group ( $\mathrm{p}=0.27, \chi^{2}$ test). Excluding patients who withdrew from the trial due to inability to tolerate the feed for three weeks, remission rate was $46 \%$ in the low LCT and $45 \%$ in the high LCT group ( $p=0.99, \chi^{2}$ test) and a fall in CDAI $\geqslant 70$ points was seen in $46 \%$ in the low LCT and $45 \%$ in the high LCT group ( $p=0.99, \chi^{2}$ test). There was also no significant difference in the mean fall in CDAI between diets: mean (SD) fall in CDAI was 37 (81) in the low LCT group and 82 (121) in the high LCT group ( $\mathrm{p}=0.11, t$ test) (fig 1$)$. Excluding dropouts due to inability to tolerate the feed, mean (SD) fall in CDAI was 42 (106) points in the low LCT group compared with 96 (134) in the high LCT group ( $\mathrm{p}=0.2, t$ test).

C REACTIVE PROTEIN

A serum CRP $<10 \mathrm{mg} / 1$ was achieved in $30 \%$ of the low LCT group and 33\% of the high LCT group by intention to treat analysis $\left(p=0.99, \chi^{2}\right.$ test) (fig 2). Excluding dropouts for noncompliance, attainment of CRP $<10 \mathrm{mg} / 1$ was $38 \%$ for the low LCT and 35\% for the high LCT diet $\left(p=0.99, \chi^{2}\right.$ test $)$. There was no significant correlation between CRP and CDAI response $(\mathrm{p}=0.39, r=0.15)$. 
HARVEY BRADSHAW INDEX

Remission defined as a HBI of $<4$ was achieved in $30 \%$ of the low LCT diet group and in 37\% of the high LCT group by intention to treat analysis $\left(p=0.77, \chi^{2}\right.$ test $)$. Excluding dropouts for non-compliance, the remission rate was $46 \%$ for the low LCT and $45 \%$ for high LCT $\operatorname{diet}\left(\mathrm{p}=0.99, \chi^{2}\right.$ test $)$.

\section{VAN HEES ACTIVITY INDEX}

There was no significant difference in response measured by VHAI with a mean (SD) fall of 26 (30) points in the low LCT group and 17 (21) in the high LCT group $(\mathrm{p}=0.54, t$ test $)$. Excluding dropouts for non-compliance, the mean (SD) fall was 25 (26) in the low LCT group and 20 (18) in the high LCT group $(\mathrm{p}=0.39, t$ test $)$.

\section{INFLAMMATORY BOWEL DISEASE QUALITY OF LIFE} INDEX

There was no significant difference in the mean improvement in inflammatory bowel disease quality of life score with a mean (SD) improvement of 18 (25) points in the low LCT group and 22 (44) points in the high LCT group ( $\mathrm{p}=0.6, t$ test $)$.

\section{WITHDRAWALS}

Overall 27 of the 54 patients $(50 \%)$ withdrew before completing three weeks of treatment. Twenty one of the 54 patients (39\%) withdrew from the trial due to inability to tolerate the feed because of unpalatability or inability to consume at least $50 \%$ of their estimated daily energy requirement for a week on two consecutive weeks. Of the remainder, 12 of the 13 low LCT group patients and 15 of the 20 high LCT group patients received at least $80 \%$ of their estimated energy requirement over the duration of the study $(p=0.36)$. Five of the six patients who did not receive $80 \%$ of their energy requirements (one low LCT and four high LCT) failed to achieve remission (CDAI $\leqslant 150$ ). There were more withdrawals due to compliance problems in the low LCT group (14 patients) than in the high LCT group (seven patients) $(p=0.09)$. Six patients $(11 \%)$ were withdrawn before they had completed three weeks of dietary therapy because of deterioration in their clinical condition.

\section{Discussion}

This randomised controlled trial has failed to show any difference in the response of active $\mathrm{CD}$ to whole protein feeds that have a high compared with a low content of long chain triglyceride. This is in agreement with a small trial of high versus low medium chain triglyceride containing feed in adolescents with CD which showed no difference in response rate between the two feeds. ${ }^{21}$ The overall remission rate of $45-46 \%$ for patients who were able to tolerate liquid feeding is lower than in some trials of whole protein feeding which showed remission rates of approximately $70-80 \%{ }^{4-6} 8$ although one trial showed a lower response rate at $36 \% .^{5}$ The cause of the lower than expected response rate is not clear; however, it is noteworthy that the two feeds used in this trial had not been previously evaluated in active CD.

The cause of the previously reported inverse correlation between LCT content of enteral feeds and response rate in CD remains unclear. It is possible that the source of fat in the feed is a factor which determines response. The fat in the two diets examined in this trial were from soyabean, palm, and canola oil sources whereas other feeds have used olive oil ${ }^{8}$ and safflower oil sources. ${ }^{2}$ Studies in mice have shown that the source of dietary lipids can affect the cytokine response to bacterial lipopolysaccharide, coconut oil and fish oil sources lowering proinflammatory cytokines compared with safflower oil containing feeds. ${ }^{22} \mathrm{~A}$ single trial has shown that fish oils may reduce the risk of relapse in $\mathrm{CD},{ }^{23}$ although an earlier study failed to show this effect. ${ }^{24}$ Fish oils are rich in n-3 fatty acids which can suppress the synthesis of interleukin $1 \beta$, interleukin $1 \alpha$, and tumour necrosis factor $\alpha .^{25}$

Linoleic acid content has been suggested as a factor determining the efficacy of enteral nutrition in active CD with higher linoleic acid content being associated with a poorer response. ${ }^{9}$ Linoleic acid is a precursor for proinflammatory eicosanoids such as leukotriene $\mathrm{B}_{4}$ and animal studies have suggested that low fat diets can induce immunomodulatory changes. ${ }^{26}$ It has been speculated that low availability of linoleic acid in the diet reduces substrate availability for the production of such proinflammatory eicosanoids. ${ }^{913}$ However, the two feeds studied in the present trial both had low linoleic acid content.

If the previously documented inverse correlation between LCT content and response is not due to the LCT itself, then possibly some other component associated with a high LCT content could be to blame. Possibilities include emulsifiers and stabilisers that are particularly likely to be present in feeds that are "ready made" rather than in powder form.

Further trials should be performed to assess the possible effects of the source of fat, stabilisers, emulsifiers, or detergents on the efficacy of enteral feeds in active CD.

Dr Keith Leiper was the Leslie Parrott Research Fellow of the National Association of Colitis and Crohn's disease.

Conflict of interest. M van der Vliet was partly funded by SHS International Ltd, Liverpool, who supplied the experimental diets. JMR and JOH have received honoraria for participating in meetings sponsored by SHS International Ltd.

1 Royall D, Jeejeebhoy KN, Baker JP, et al. Comparison of amino acid v peptide based enteral diets in active Crohn's disease: clinical and nutritional outcome. Gut 1994;35:783-7.

2 O'Morain C, Segal AW, Levi AJ. Elemental diet as primary treatment of acute Crohn's disease: a controlled trial. $B M \mathcal{F}$ 1984;288:1859-62.

3 Saverymuttu S, Hodgson HJF, Chadwick VS. Controlled trial comparing prednisolone with an elemental diet plus non absorbable antibiotics in active Crohn's disease. Gut 1985;26:994-8.

4 Park HR, Galloway A, Danesh JZD, et al. Double blind controlled trial of elemental and polymeric diets as primary therapy in active Crohn's disease. Eur 7 Gastroenterol Hepatol 1991;3:483-90.

5 Giaffer MH, North G, Holdsworth CD. Controlled trial of polymeric versus elemental diet in treatment of active
Crohn's disease. Lancet 1990;335:816-19.

6 Raouf AH, Hildrey V, Daniel J, et al. Enteral feeding as sole treatment for Crohn's disease: controlled trial of whole treatment for Crohn's disease: controlled trial of whole
protein $\mathrm{v}$ amino acid based feed and a case study of dietary challenge. Gut 1991;32:702-7. 
7 Rigaud D, Cosnes J, Le Quintrec Y, et al. Controlled trial comparing two types of enteral nutrition in treatment of comparing two types of enteral nutrition in
active Crohn's disease. Gut 1991;32:1492-7.

8 González-Huix F, de León R, Fernández-Bañares F, et al. Polymeric enteral diets as primary treatment of active Crohn's disease: a prospective steroid controlled trial. Gut 1993;34:778-82.

9 Fernández-Bañares F, Cabré E, González-Huix F, et al. Enteral nutrition as primary therapy in Crohn's disease. Gut 1994;34(suppl 1):S55-9.

10 Middleton SJ, Rucker JT, Kirby GA, et al. Long-chain triglycerides reduce the efficacy of enteral feeds with active Crohn's disease. Clin Nutr 1995;14:229-36.

11 Evans RC, Rhodes JM. Understanding the mechanism of dietary therapy in Crohn's disease - meta-analysis of polymeric enteral feeding studies and pilot study of maintenance with low fibre/low fat diet. Gut 1996;38:A637

12 Nagel E, Schattenfroh S, Buhner S, et al. Animal experimental studies of ultrastructural changes in the lamina propria of the ileum caused by dietary fats and comparison with cytopathology in Crohn's disease. $Z$ Gascomparison with cytopath

13 Miura S, Tsuzuki Y, Hokari R, et al. Modulation of intestinal immune system by dietary Crohn's disease. f Gastroenterol Hepatol 1998;13:1183-90.

14 Best WR, Becktel JM, Singleton JW, et al. Development of a Crohn's disease activity index. Gastroenterology 1996;70 439-44.

15 Elia M. Artificial nutritional support. Med Int 1990;82: 3392-6.

16 Schofield WN, Schofield C, James WPT. Basal metabolic rate-review and predictions, together with an annotated bibliography of source material. Hum Nutr Clin Nutr 1985 39(suppl 1):5-96.
17 Harvey RF, Bradshaw JM. A simple index of Crohn's disease activity. Lancet 1980;i:514.

18 van Hees PAM, van Elteren PH, van Lier HJJ, et al. An index of inflammatory activity in patients with Crohn's disease. Gut 1980;21:279-86.

19 Irvine EJ, Feagon B, Rochon J, et al. Quality of life: a valid and reliable measure of therapeutic efficacy in the treatment of inflammatory bowel disease. Gastroenterology 1994;106:287-96.

20 Machin D, Campbell MJ. Statistical tables for the design of clinical trials. Oxford: Blackwell, 1987.

21 Khoshoo V, Reifen R, Neuman MG, et al. Effect of low- and high-fat, peptide-based diets on body composition and disease activity in adolescents with active Crohn's disease. FPEN J Parenter Enteral Nutr 1996;20:401-5.

22 Sadeghi S, Wallace FA, Calder PC. Dietary lipids modify the cytokine response to bacterial lipopolysaccharide in mice. Immunology 1999;96:404-10.

23 Belluzzi A, Brignola C, Campieri M, et al. Effect of an enteric coated fish oil preparation on relapses in Crohn's disease. N Engl f Med 1996;334:1557-60.

24 Lorenz-Meyer H, Bauer P, Nicolay C, et al. Omega-3 fatty acids and low carbohydrate diet for maintenance of remission in Crohn's disease. Scand F Gastroenterol 1996;31:77885.

25 Endres S, Ghorbani R, Kelly VE, et al. The effect of dietary supplementation with $n-3$ polyunsaturated fatty acids on the synthesis of interleukin- $1 \beta$ and tumour necrosis factor by mononuclear cells. $N$ Engl f Med 1989;320:265-71.

26 Morrow WJW, Homsy J, Swanson CA, et al. Dietary fat influences the expression of autor $1 \mathrm{pr} / 1 \mathrm{pr}$ mice. Immunology 1986;59:439-43. 